\title{
Active transport of particulate organic carbon and nitrogen by vertically migrating zooplankton in the Sargasso Sea
}

\author{
Astrid Schnetzer ${ }^{1, *}$, Deborah K. Steinberg ${ }^{2}$ \\ ${ }^{1}$ Department of Biological Sciences, University of Southern California, 3616 Trousdale Parkway, AHF 301, \\ Los Angeles, California 90089-0371, USA \\ ${ }^{2}$ Virginia Institute of Marine Science, PO Box 1346, Gloucester Point, Virginia 23062, USA
}

\begin{abstract}
Diel vertically migrating zooplankton can contribute significantly to dissolved carbon and nutrient export by respiring and excreting surface-ingested particulate organic matter below the mixed layer. Active export of particulate organic carbon (POC) and particulate organic nitrogen (PON) due to defecation at depth has rarely been considered in export budgets. We measured the gut passage time (GPT) of common migrant species at the Bermuda Atlantic Time-series Study (BATS) site, using the gut fluorescence method, to determine whether GPT is slow enough to allow active export of POC and PON to depth. Mean GPT for the copepods Pleuromamma xiphias and Euchirella messinensis was 191 and 114 min, respectively, and for the euphausiids Thysanopoda aequalis and Euphausia brevis (analyzed together) was $41 \mathrm{~min}$, exceeding previously reported GPT for nonmigrating zooplankton by a factor of 6 . Between 18 and $81 \%$ of the initial gut pigment was retained in zooplankton guts upon descent below a mixed layer of $150 \mathrm{~m}$. By comparing pigment ingestion rates (gut fluorescence technique) with total ingestion rates (CHN analysis of fecal material), we estimated that 71 to $85 \%$ of the migrant diet originated from non-plant material, which we included in our estimates of active POC/PON export. We applied the mean weight-specific active POC/PON export rate for the species examined to the total migratory zooplankton biomass using data from the BATS zooplankton time-series. Mean active POC (PON) flux at BATS was $0.94 \mathrm{mg} \mathrm{C} \mathrm{m}^{-2} \mathrm{~d}^{-1}$ $\left(0.18 \mathrm{mg} \mathrm{N} \mathrm{m}^{-2} \mathrm{~d}^{-1}\right)$ and the maximum was $5.27 \mathrm{mg} \mathrm{C} \mathrm{m}^{-2} \mathrm{~d}^{-1}\left(1.02 \mathrm{mg} \mathrm{N} \mathrm{m}^{-2} \mathrm{~d}^{-1}\right)$, corresponding to a mean of $3 \%$ ( $4 \%$ ) and a maximum of $18 \%$ ( $20 \%$ ) of the mean gravitational POC (PON) flux measured by sediment traps at $150 \mathrm{~m}$. Migrants also contributed significantly to passive flux via production of sinking fecal pellets during the night in surface waters. This passive flux exceeded active POC flux by $\sim 10$-fold. Freshly released feces by migrators at depth could be a valuable food source for mesopelagic organisms, in contrast to feces produced in surface waters which decompose while settling through the water column.
\end{abstract}

KEY WORDS: Zooplankton · Vertical migration $\cdot$ Gut evacuation rate $\cdot$ Gut fluorescence $\cdot$ Particulate organic carbon · Particulate organic nitrogen · Export flux · Sargasso Sea · Bermuda Atlantic Timeseries Study (BATS)

Resale or republication not permitted without written consent of the publisher

\section{INTRODUCTION}

The 2 main biological pathways by which carbon and nutrients are exported from the mixed layer to the deep sea (biological pump) are passive transport by

*E-mail: astrids@usc.edu sinking particles such as marine snow or fecal pellets (Paffenhoefer \& Knowles 1979, Fowler \& Knauer 1986, Michaels \& Silver 1988) and active transport by zooplankton vertical migration (Longhurst \& Harrison 1988, 1989, Dam et al. 1995, Hays et al. 1997, Le Borgne \& Rodier 1997, Zhang \& Dam 1997, Steinberg et al. 2000, Al-Mutairi \& Landry 2001). Diel migrant zooplankton feed in the surface layers at night and 
before dawn descend to daytime residence depths of several hundred meters. Migrants can actively contribute to export flux by respiring, excreting and defecating surface-ingested carbon and nitrogen below the mixed layer. Steinberg et al. (2000) recently showed that vertically migrating zooplankton transport significant amounts of both dissolved inorganic carbon (DIC) by respiration and dissolved organic carbon (DOC) by excretion below the mixed layer at the Bermuda Atlantic Time-series Study (BATS) site-located in the western North Atlantic subtropical gyre. Other studies of active transport in the subtropical gyres also indicate significant transport of DIC and dissolved inorganic nitrogen (DIN) (Longhurst et al. 1990, Dam et al. 1995, Al-Mutairi \& Landry 2001). What has not been previously measured at BATS, and is rarely included in studies of export processes, is active transport of particulate organic carbon and nitrogen (POC/PON) due to defecation at depth.

Migrating zooplankton will contribute to active transport of POC/PON to depth if their gut passage times (GPT) are slow enough and their migration speeds are fast enough to allow them to void a portion of their ingested food below the mixed layer. Angel (1985) suggested that only larger diel migrators such as fish are likely to contribute to active transport of POC,

Table 1. Gut evacuation experiments. Each date represents an individual experiment. Copepods: P, Pleuromamma xiphias and E, Euchirella messinensis; Euphausiids: T/Eb,Thysanopoda aequalis/Euphausia brevis; Exp. Temp.: experimental (ambient surface water) temperatures during incubations; ML Temp.: in situ mixed layer temperature integrated over upper $150 \mathrm{~m}$; GPT: gut passage time corrected for in situ ML temperature using a $Q_{10}$ of 2.21 (Dam \& Peterson 1988). ${ }^{*}$ No decrease in gut pigment detected within the initial $120 \mathrm{~min}$ (excluded from calculating the mean)

\begin{tabular}{|lrrcrc|}
\hline Expt & $\begin{array}{c}\text { Date } \\
(\mathrm{mo} / \mathrm{d} / \mathrm{yr})\end{array}$ & $\begin{array}{c}\text { Depth of tow } \\
(\mathrm{m})\end{array}$ & $\begin{array}{c}\text { Exp. Temp. } \\
\left({ }^{\circ} \mathrm{C}\right)\end{array}$ & $\begin{array}{c}\text { ML Temp. } \\
\left({ }^{\circ} \mathrm{C}\right)\end{array}$ & $\begin{array}{c}\text { GPT } \\
(\mathrm{min})\end{array}$ \\
\hline P1 & $5 / 5 / 98$ & 87 & 23.0 & 19.9 & 210 \\
P2 & $6 / 3 / 98$ & 87 & 23.0 & 20.0 & 99 \\
P3 & $6 / 3 / 98$ & 130 & 23.0 & 20.0 & 184 \\
P4 & $6 / 30 / 98$ & 87 & 27.0 & 20.6 & 265 \\
P5 & $7 / 1 / 98$ & 104 & 26.0 & 20.6 & ${ }^{*}$ \\
P6 & $8 / 13 / 98$ & 130 & 27.1 & 21.8 & 195 \\
Mean (SD) & & 104 & 24.9 & 20.5 & $191(60)$ \\
E1 & $6 / 4 / 98$ & 173 & 23.3 & 20.0 & 110 \\
E2 & $7 / 3 / 98$ & 130 & 26.2 & 20.6 & 88 \\
E3 & $8 / 12 / 98$ & 130 & 27.1 & 21.8 & 120 \\
E4 & $11 / 17 / 98$ & 98 & 24.1 & 22.4 & 97 \\
E5 & $11 / 19 / 98$ & 156 & 25.2 & 22.4 & 153 \\
Mean (SD) & & 137 & 25.2 & 21.4 & $114(25)$ \\
T/Eb1 & $4 / 16 / 98$ & 52 & 19.5 & 19.7 & 40 \\
T/Eb2 & $5 / 8 / 98$ & 130 & 22.1 & 19.8 & 26 \\
T/Eb3 & $5 / 18 / 99$ & 130 & 23.4 & 20.2 & 37 \\
T/Eb4 & $5 / 20 / 99$ & 130 & 23.4 & 20.2 & 99 \\
T/Eb5 & $5 / 27 / 99$ & 173 & 23.5 & 20.2 & 15 \\
T/Eb6 & $5 / 27 / 99$ & 144 & 23.5 & 20.2 & 26 \\
Mean (SD) & & 127 & 22.6 & 20.1 & $41(30)$ \\
\hline
\end{tabular}

because of their longer GPT. A number of studies have shown that crustacean guts are often cleared within 45 min or less (e.g. Dagg \& Wyman 1983, Morales et al. 1991, Wlodarczyk et al. 1992, Landry et al. 1994), suggesting most of the gut content would be defecated before the crustaceans reach the bottom of the mixed layer. However, the crustaceans examined in these previous studies were epipelagic species or were not strong diel vertical migrants. Until now only a small number of studies have focused on species performing xtensive diel migrations. These studies report GPT for strong migrants exceeding those of non-migrant species or optional migrants by 3 - to 4 -fold, allowing for active export of particulate organic matter from the mixed layer (Smith \& Lane 1988, Flint et al. 1991, Morales et al. 1993, Atkinson et al. 1996, Pakhomov et al. 1997, Morales 1999).

We tested whether GPT of common diel vertical migrators at BATS is sufficiently long to allow for transport of POC/PON to depth by measuring migrator gut pigment using the gut fluorescence method (Mackas \& Bohrer 1976). This information was combined with previously reported swim speeds to estimate POC/ PON remaining in migrator guts that would be defecated at depth. Results from individual species were extrapolated to the total migrating community to evaluate the relative importance of active POC/PON flux compared to active DOC and DIC flux by migrators and to passive sinking of POC/PON measured with sediment traps at BATS.

\section{MATERIALS AND METHODS}

Zooplankton collection. Zooplankton were collected at the US JGOFS BATS station in the Sargasso Sea $\left(31^{\circ} 45^{\prime} \mathrm{N}, 64^{\circ} 10^{\prime} \mathrm{W}\right)$ by vertical tows within the surface $175 \mathrm{~m}$ at night (Table 1). Tows were performed on monthly BATS cruises between April and November 1998 and in May 1999. We used a $2 \mathrm{~m}$ diameter net with a mesh size of $500 \mu \mathrm{m}$ and a nonfiltering, large-volume cod end that maintains the zooplankton in good condition (Steinberg et al. 2000).

Gut evacuation experiments. The amount of plant pigment in the guts of freshly collected zooplankton was measured over time to determine gut evacuation rates (Mackas \& Bohrer 1976). Contents of the cod end were carefully poured into a tray filled with 
$0.2 \mu \mathrm{m}$ filtered seawater and healthy, active migrators-copepods Pleuromamma xiphias (Metridiidae) and Euchirella messinensis (Aetideidae), and the euphausiids Thysanopoda aequalis and Euphausia brevis (Euphausiidae)-were incubated at ambient surface temperatures in the dark. Incubation temperatures ranged from 19.5 to $27.1^{\circ} \mathrm{C}$ (Table 1 ). The average number of migrators per bottle was 20 for $P$. xiphias, 15 for E. messinensis and 3 for T. aequalis/E. brevis. The 2 euphausiid species were combined to obtain enough animals for analysis and avoid extended picking time and thus loss of gut material prior to incubation. The first time point was taken immediately after the cod end was recovered, and the time required to pick zooplankton for the first time point ( $\sim \mathrm{min})$ was taken into account for each subsequent time point. Animals were picked from the same tow for a maximum of $30 \mathrm{~min}$ (in most experiments 30 min was sufficient to collect all zooplankton needed for a complete gut evacuation experiment). At each time point the entire bottle content was poured through a $333 \mu \mathrm{m}$ mesh sieve. Animals were rinsed with $0.2 \mu \mathrm{m}$ filtered seawater, removed from the sieve with forceps and frozen $\left(-20^{\circ} \mathrm{C}\right)$ immediately for later gut fluorescence analysis. Time points were taken every 15 min within the first hour, followed by $30 \mathrm{~min}$ or $1 \mathrm{~h}$ intervals up to 3 or $4 \mathrm{~h}$, depending on the number of crustaceans collected. An additional time point after $12 \mathrm{~h}$ was included as a control to measure background levels of gut pigment retained by starving animals.

Gut fluorescence analysis. Frozen samples were analyzed within 2 mo of collection. Animals were thawed in the laboratory, their species identification confirmed under a dissecting microscope (in dim light to prevent pigment degradation), and total carapace length was measured. Groups of zooplankton were homogenized in $450 \mu \mathrm{l}$ of $90 \%$ acetone in a tissue homogenizer and then the total volume was brought up to $1 \mathrm{ml}$ with $90 \%$ acetone. Reduced extraction volumes and small-sized cuvettes (Takatsuji et al. 1997) enabled determination of gut pigment from small numbers of copepods ( 3 to 6 ) and euphausiids (1 to 4) per subsample. On average, 3 subsamples were analyzed per time point. Gut pigment was extracted overnight in the freezer and then centrifuged at $3500 \mathrm{rpm}(867 \times g)$ for $4 \mathrm{~min}$ (Eppendorf 5415 microcentrifuge). Fluorescence of $200 \mu \mathrm{l}$ of supernatant was measured before and after acidification with $10 \mu \mathrm{l}$ of $5 \% \mathrm{HCl}$ using a Turner TD 700 fluorometer. The chlorophyll and phaeopigment content of each crustacean was calculated using equations from Parsons et al. (1984). Background levels of gut pigment for starved animals were subtracted from all gut pigment data and the resultant 'net' gut pigment is reported as chlorophyll a ( $\mathrm{chl} \mathrm{a}$ ) equivalents (equiv.) per copepod or euphausiid gut.
There is wide agreement that a proportion of chl a in crustacean guts degrades into non-fluorescent forms. Estimates of chl a loss range from 11 to $98 \%$, depending on factors such as diet, food concentration, species investigated or even season (Conover et al. 1986, Dagg \& Walser 1987, Dam \& Peterson 1988, Landry et al. 1994, Pasternak 1994, Perissinotto \& Pakhomov 1996). As we did not measure pigment destruction directly in our experiments, we assumed a $33 \%$ chl a loss, a value consistent with destruction estimates reported from the majority of previous studies (see 'Discussion'), which increased pigment values by a factor of 1.5.

Calculation of gut evacuation rate. The decrease in gut pigment over time has been described by simple linear regression (Bochdansky \& Deibel 2001), but more commonly by using an exponential curve fit (Dam \& Peterson 1988, Ellis \& Small 1989, Flint et al. 1991, Atkinson et al. 1996). We compared gut evacuation rates calculated with both models using the following equations:

$$
\begin{gathered}
P_{t}=P_{0}-\mathrm{k} t \text { (linear model) } \\
P_{t}=P_{0} \mathrm{e}^{-\mathrm{k} t} \text { (exponential model) }
\end{gathered}
$$

where $P_{t}$ is the pigment level (ng chl a equiv. ind. ${ }^{-1}$ ) at time $t, P_{0}$ is the pigment level at the onset of the experiment after correction for background fluorescence (ng chl a equiv. ind. ${ }^{-1}$ ), and $\mathrm{k}$ is the constant gut evacuation rate $\left(\mathrm{min}^{-1}\right)$ for the linear model or the instantaneous gut evacuation rate in the exponential model. GPT (min) is the reciprocal of $\mathrm{k}$. We determined which model was more appropriate by comparing the r-values by a randomized block design ANOVA (SAS 1985) after transforming r-values to $z$-distribution variables following Zar (1984). For each experiment, GPT was corrected for differences in incubation temperature (ambient surface water) and in situ temperature (integrated over the upper $150 \mathrm{~m}$ - the mean temperature migrators experience before leaving the mixed layer) using a $Q_{10}$ of 2.21 (Dam \& Peterson 1988). The temperature range in the upper $150 \mathrm{~m}$ during shipboard experiments was small and varied between 19.7 and $22.4^{\circ} \mathrm{C}$ (Table 1 ).

Plant carbon ingestion rates (ng chl a equiv. ind.-1 $\mathrm{h}^{-1}$ ) for each copepod species and the euphausiids were computed by multiplying mean gut content (ng chl a equiv. ind..$\left.^{-1}\right)$ by the gut evacuation rate $\mathrm{k}\left(\mathrm{h}^{-1}\right)$ (Dam \& Peterson 1988, Morales et al. 1990, Pasternak 1994, Irigoien 1998). This method is widely used, but includes uncertainties in carbon to pigment ratios or level of pigment destruction (see 'Discussion').

Fecal pellet production rates. Gut pigment analysis does not take into account food derived from non-plant material; thus absolute fecal carbon transport for omnivorous species based on the gut fluorescence method could be underestimated. Therefore, we separately conducted fecal pellet production experiments $(n=14)$ 
and measured total POC and PON defecated using $\mathrm{CHN}$ analysis. One liter jars were filled with $0.2 \mu \mathrm{m}$ filtered seawater, and 10 to 15 euphausiids or 20 to 25 copepods were picked immediately after retrieval of the net and added to jars. Fecal pellet traps with a $333 \mu \mathrm{m}$ mesh were inserted at the bottom of jars to separate animals from feces produced and prevent re-ingestion. After a mean period of $60 \mathrm{~min}$ (range $=45$ to $75 \mathrm{~min}$ ) animals were removed and their feces were filtered onto precombusted Whatman GF/F glass fiber filters $\left(450^{\circ} \mathrm{C}\right.$ for $4 \mathrm{~h}$ ) and frozen for later CHN analysis. The jars and fecal pellet traps were carefully rinsed with $0.2 \mu \mathrm{m}$ filtered seawater to assure fecal pellet recovery was as complete as possible. Material that was positively identified as non-fecal material (e.g. parts of antennulae), but occasionally retained on the filters, was carefully removed using tweezers prior to freezing. Equal volumes of filtered seawater $(0.2 \mu \mathrm{m})$ were filtered onto precombusted filters for use as blanks. In the laboratory, samples were thawed, dried, fumed with concentrated $\mathrm{HCl}$ to remove inorganic carbon, and redried. Total POC and PON of the fecal material was analyzed with a Control Equipment Corporation (CEC) 240-XA Elemental analyzer. After we measured the total amount of POC/PON defecated, we calculated defecation rates for all species and corrected for a mean in situ temperature of $20.5^{\circ} \mathrm{C}$ using a $Q_{10}$ of 2.21 (Dam \& Peterson 1988). Based on these defecation rates, we were able to calculate total carbon ingestion rates for all species assuming an assimilation efficiency of $70 \%$ (Conover 1978). By comparing total carbon ingestion (based on CHN data) to plant carbon ingestion (based on gut fluorescence data), we determined the amount of diet derived from non-plant material (detritus or other animals). Pigment ingestion rates were converted into carbon values using a C:chl a ratio of 50 for Sargasso Sea phytoplankton (range $=33$ to 160 ; Goericke \& Welschmeyer 1998; see 'Discussion').

Calculation of export flux. Gut evacuation rates determined in our experiments and published migration speeds were used to calculate the amount of carbon defecated by migrators during their descent, and that remaining in animal guts for defecation at depth. Weight-specific gut evacuation rates were calculated for each of the 2 copepod species and the euphausiids and the amount of gut content left at 150, 200 and $300 \mathrm{~m}$ depth was computed. The mean amount of carbon released at depth from all species was applied to total migrant biomass using the following equation:

$$
E_{z}=C \times M B
$$

where $E_{z}$ is active POC export flux at depth $z$ (mg C $\mathrm{m}^{-2} \mathrm{~d}^{-1}$ ), $C$ is the average amount of carbon (for all species normalized for body carbon content) left in the guts after descent to depth $z$ (mg C [mg body $\mathrm{C}^{-1} \mathrm{~d}^{-1}$ ) and $M B$ is total (>200 $\mu \mathrm{m}$ size range) migrant biomass $\left(\mathrm{mg} \mathrm{C} \mathrm{m}{ }^{-2}\right)$ integrated over the upper $150 \mathrm{~m}$ of the water column. Time-series data on zooplankton biomass and species composition at BATS have been collected as part of the BATS program since 1994. Zooplankton day and night biomass is sampled on monthly cruises to a depth of approximately $200 \mathrm{~m}$ (details of collection in Madin et al. 2001). We calculated migrant biomass by subtracting day from night biomass integrated over the upper $150 \mathrm{~m}$ using data from April 1994 to December 1999. Specific dry weights for Pleuromamma xiphias and the euphausiids were determined in a previous study (Steinberg et al. 2000). Dry weight for Euchirella messinensis was measured for groups $(n=6)$ of 8 copepods, which were previously collected and stored frozen. Samples were thawed, dried at $60^{\circ} \mathrm{C}$ for $24 \mathrm{~h}$ and weighed.

We applied C:N ratios measured for migrant fecal pellets to active POC export rates to calculate active PON flux, and compared active migrator POC/PON export flux to passive POC/PON flux measured by sediment traps at 150, 200 and $300 \mathrm{~m}$ at BATS using sediment trap data from January 1994 to December 1999 (for details on BATS sediment trap measurements see Steinberg et al. 2001).

\section{RESULTS}

\section{Gut fluorescence analysis}

All gut pigment data were corrected for background levels determined from starved animals. After starving animals for $12 \mathrm{~h}$, a mean of 8,18 and $10 \%$ of initial gut pigment was still left in the guts of Pleuromamma xiphias, Euchirella messinensis and Thysanopoda aequalis/Euphausia brevis, respectively.

The mean initial gut pigment content for Pleuromamma xiphias was $19.9 \mathrm{ng} \mathrm{chl}$ a equiv. ind ${ }^{-1}$ (range = 16.3 to $29.7 \mathrm{ng}$ chl $a$ equiv. ind. ${ }^{-1}$ ) and $10.4 \mathrm{ng} \mathrm{chl} \mathrm{a}$ equiv. ind..$^{-1}$ for both Euchirella messinensis and the euphausiids (range $=7.8$ to 13.9 and 5.0 to $20.5 \mathrm{ng} \mathrm{chl} a$ equiv. ind. ${ }^{-1}$, respectively). P. xiphias guts initially contained significantly more pigment than the other species ( $p<0.05, t$-test). Generally, initial gut pigment levels were slightly higher for zooplankton sampled in spring and early summer, but data were not sufficient to statistically test seasonal variations in gut pigment levels. Initial gut pigment level was positively correlated with animal size for the copepods $E$. messinensis and $P$. xiphias pooled together $\left(\mathrm{r}^{2}=0.70, \mathrm{p}<0.01\right)$ but no significant correlation was found for the euphausiids or either of the copepod species separately (Fig. 1). Variability in initial gut fluorescence can in part be explained by the individual feeding history prior to col- 
Table 2. Regression analysis for gut evacuation data from experiments with copepod Pleuromamma xiphias (P). Time span of incubation was 60 and 120 min. r exp. and r lin.: r-values obtained from exponential (exp.) and linear (lin.) curve fits; r-values were compared using a randomized block design ANOVA (see 'Results')

\begin{tabular}{|lcccc|}
\hline \multirow{2}{*}{ Expt } & \multicolumn{2}{c}{$60 \mathrm{~min}$} & \multicolumn{2}{c|}{$120 \mathrm{~min}$} \\
& r exp. & r lin. & r exp. & r lin. \\
\hline P1 & 0.901 & 0.893 & 0.875 & 0.856 \\
P2 & 0.846 & 0.871 & 0.966 & 0.952 \\
P3 & 0.843 & 0.834 & 0.958 & 0.954 \\
P4 & 0.833 & 0.817 & 0.827 & 0.788 \\
P6 & 0.711 & 0.716 & 0.876 & 0.796 \\
& & & & \\
\hline
\end{tabular}

lecting the specimens, as some migrants could have only recently arrived in the surface layer to feed, while others might have begun feeding earlier.

\section{Gut passage times}

The gut evacuation rate $(\mathrm{k})$ depends on the model applied to the data and the length of time over which the experiment is conducted. We compared the r-values obtained from linear and exponential models for 2 different time spans for all species (time spans

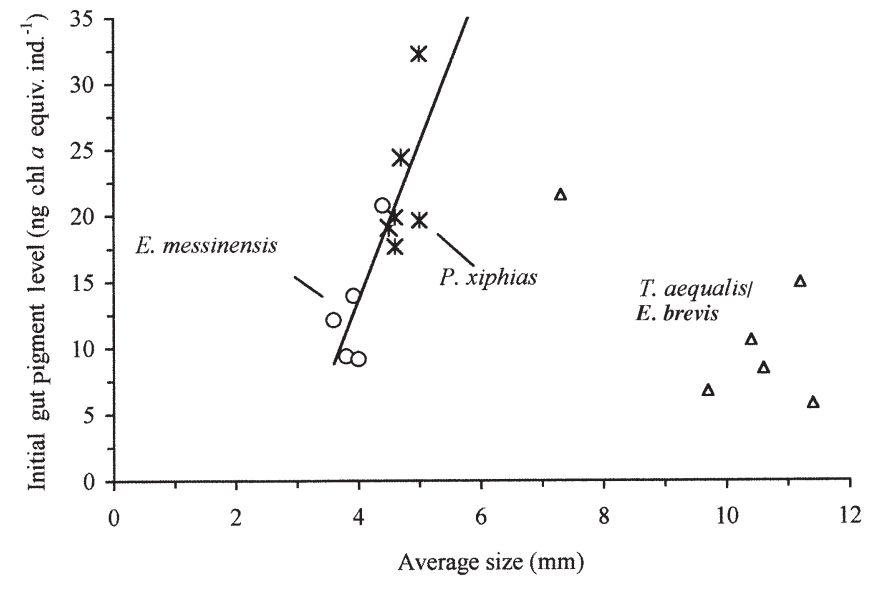

Fig. 1. Relationship between zooplankton size and initial gut pigment. Data for copepods Pleuromamma xiphias and Euchirella messinensis and euphausiids Thysanopoda aequalis/ Euphausia brevis are shown. A significant positive correlation was found for the pooled data set for the copepods $P$. xiphias and E. messinensis $\left(y=11.866 \mathrm{x}-33.857, \mathrm{n}=11, \mathrm{r}^{2}=0.7, \mathrm{p}<\right.$ 0.01 ), while no significant correlation was found for each copepod species separately or for the euphausiids

tested were 60 and 120 min for both copepods and 60 and $90 \mathrm{~min}$ for the euphausiids). For Pleuromamma xiphias, r-values (shown in Table 2) for the exponential model and a time span of 120 min were significantly

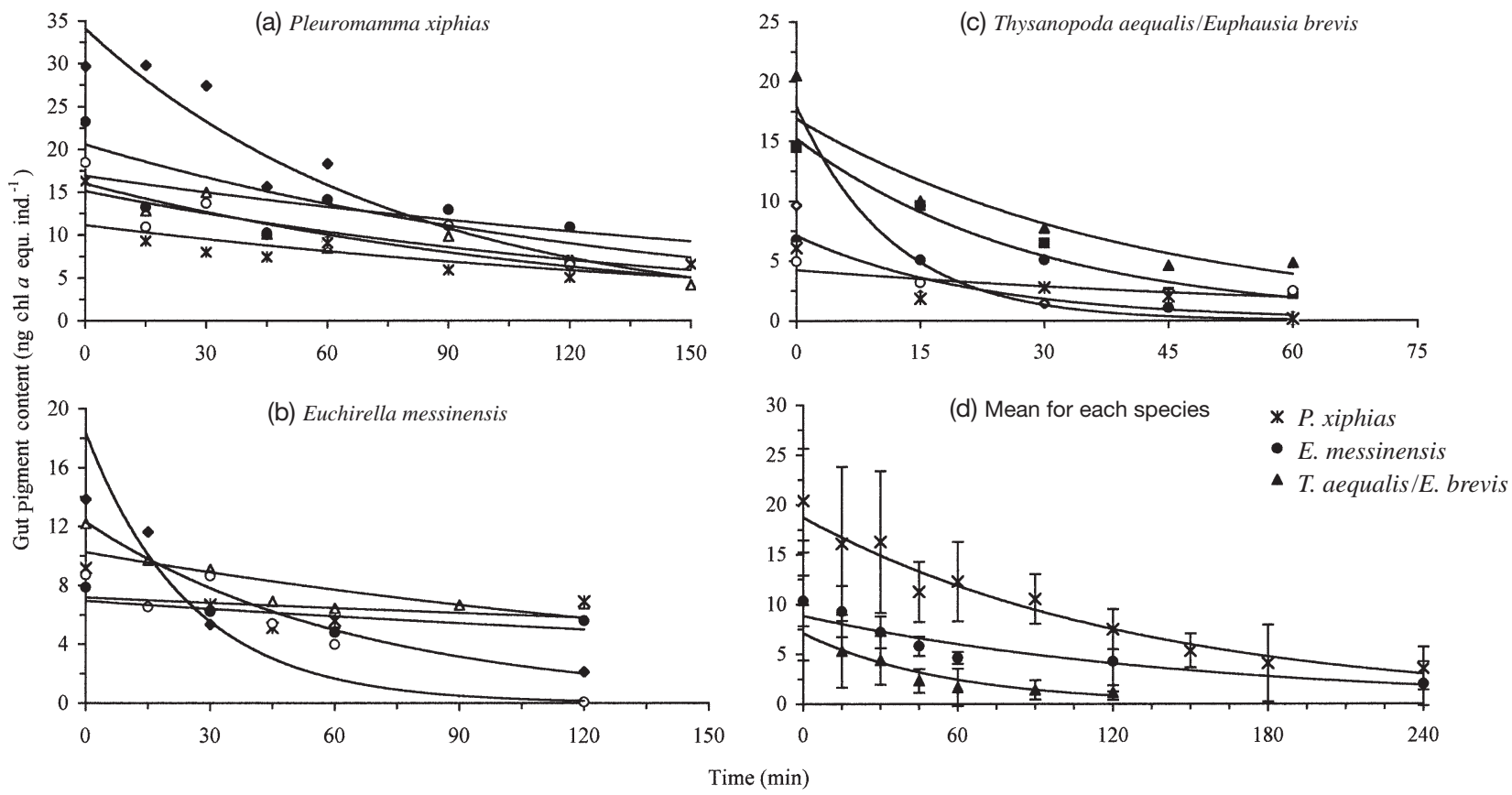

Fig. 2. Gut evacuation experiments. (a) Copepod Pleuromamma xiphias ( $\mathrm{n}=6)$, (b) copepod Euchirella messinensis $(\mathrm{n}=5)$, (c) euphausiids Thysanopoda aequalis/Euphausia brevis $(\mathrm{n}=5)$, and (d) mean values for all species. Each symbol in (a) to (c) denotes a different experiment. Note: different scales on $x$-axis; gut pigment data for the euphausiids in (c) are only shown for the first hour of the experiment 


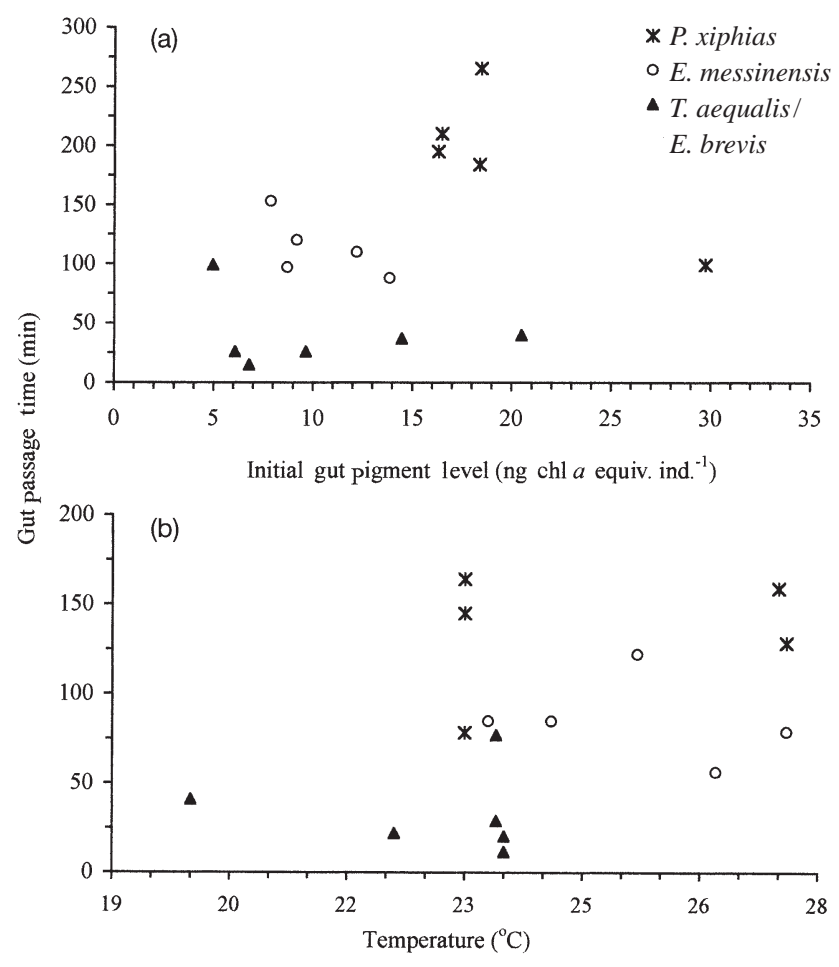

Fig. 3. Comparison of (a) initial gut pigment level versus gut passage time, and (b) incubation temperature versus gut passage time. Data for copepods Pleuromamma xiphias and Euchirella messinensis and euphausiids Thysanopoda aequalis/Euphausia brevis are shown. Note: gut passage times in (a) are corrected for in situ temperature, while those in (b) are not

greater than those for the exponential model over 60 min or the linear model over either time span (randomized block design ANOVA, $\mathrm{p}<0.05)$. Although not statistically significant, the majority of r-values for Euchirella messinensis and Thysanopoda aequalis/ Euphausia brevis were greatest for the exponential model and a time span of 60 min (data not shown). Thus, an exponential model was used for all species (Fig. 2), with an experimental time span of $120 \mathrm{~min}$ used for $P$. xiphias and $60 \mathrm{~min}$ for E. messinensis and the euphausiids.
GPT varied significantly between the different species (1-way ANOVA; $\mathrm{p}<0.01$ ). Pleuromamma xiphias had a mean GPT of $191 \mathrm{~min}$ (range = 99 to $265 \mathrm{~min}$ ), followed by Euchirella messinensis with a mean GPT of $114 \mathrm{~min}$ (range = 88 to $153 \mathrm{~min}$ ) and Thysanopoda aequalis/Euphausia brevis (mean GPT $=41 \mathrm{~min}$; range = 15 to $99 \mathrm{~min}$; Table 1). No significant relation was found between GPT and initial gut pigment levels (Fig. 3a) and incubation temperature (Fig. 3b) for any of the species examined. Mean plant carbon ingestion rates based on gut pigment ranged from 0.38 to $1.01 \mu \mathrm{g} \mathrm{C}$ ind. ${ }^{-1} \mathrm{~h}^{-1}$ (Table 3).

\section{Fecal pellet production}

To avoid underestimation of POC/PON export flux by basing our calculations exclusively on gut pigment measurements and because gut content analyses of the investigated species indicate omnivorous feeding (Schnetzer \& Steinberg 2002), we conducted experiments on fecal pellet production with freshly collected animals incubated in $0.2 \mu \mathrm{m}$ filtered seawater. Table 3 compares total ingestion rates based on $\mathrm{CHN}$ analysis of fecal pellets with plant carbon ingestion rates derived from gut pigment data. Differences in ingestion rates were used to determine diet preferences. Approximately $29 \%$ of POC defecated by Pleuromamma xiphias originated from plant material, but only 17 and $15 \%$ in Euchirella messinensis and Thysanopoda aequalis/Euphausia brevis, respectively (Table 3). Due to the high variance in ingestion rates based on CHN analysis (Table 3 ) and varying numbers of replicates, ingestion rates were not tested for significant differences between species.

The molar C:N ratio of fecal pellets did not differ significantly between species, with a mean fecal pellet C:N of 6.3 for Pleuromamma xiphias, 5.9 for Euchirella messinensis and 5.7 for Thysanopoda aequalis/Euphausia brevis. These ratios are in the low range of $\mathrm{C}: \mathrm{N}$ ratios measured for copepod fecal pellets (see summary in Morales 1987).

Table 3. Migrator ingestion rates. Ingestion rate I: based on gut fluorescence data; ingestion $=$ mean gut content $\times$ gut evacuation constant k. Pigment data are converted into carbon using a C:chl a ratio of 50. n: number of experiments conducted; ingestion rate II: based on CHN analysis of fecal material; ingestion was calculated assuming an assimilation efficiency of $70 \%$. Mean values are given, with ranges in parentheses. Plant material: percentage of total carbon ingestion derived from autotrophic diet.

Note: all experiments were conducted in $0.2 \mu \mathrm{m}$ filtered seawater

\begin{tabular}{|c|c|c|c|c|c|c|c|}
\hline Species & $\begin{array}{l}\text { Ingest } \\
\text { Gut pigment }\end{array}$ & $\begin{array}{l}\left(\mu \mathrm{g} \mathrm{C} \mathrm{h}^{-1} \text { ind }^{-1}\right) \\
\text { on rate I }\end{array}$ & $\mathrm{n}$ & $\begin{array}{l}\text { Ingestio } \\
\mathrm{CHN} \text { analysis }\end{array}$ & $\begin{array}{l}\text { on rate II } \\
\left(\mu \mathrm{g} \mathrm{C} \mathrm{h}^{-1} \text { ind. }^{-1}\right)\end{array}$ & $\mathrm{n}$ & $\begin{array}{c}\text { Plant material } \\
(\%)\end{array}$ \\
\hline Pleuromamma xiphias & 0.38 & $0.21-0.90$ & 5 & 1.30 & $0.56-1.80$ & 3 & 29 \\
\hline Euchirella messinensis & 0.29 & $0.15-0.47$ & 5 & 1.76 & $0.30-3.44$ & 4 & 17 \\
\hline $\begin{array}{l}\text { Thysanopoda aequalis/ } \\
\text { Euphausia brevis }\end{array}$ & 1.01 & $0.15-1.54$ & 6 & 6.77 & $0.44-14.3$ & 7 & 15 \\
\hline
\end{tabular}




\section{Zooplankton abundance and migratory biomass}

Pleuromamma xiphias, Euchirella messinensis, Thysanopoda aequalis and Euphausia brevis were abundant in night tows at BATS throughout this study. Mean body length $( \pm \mathrm{SD})$ measured for 30 individuals for each of the copepod species, was $4.7 \pm 0.2 \mathrm{~mm}$ for $P$. xiphias, $3.9 \pm 0.3 \mathrm{~mm}$ for E. messinensis, and for 30 individual euphausiids (T. aequalis/E. brevis) $10.1 \pm$ $1.5 \mathrm{~mm}$. The larger zooplankton size classes (>2 mm), to which the species examined belong, constitute $56 \%$ of the total migrant community at BATS (Madin et al. 2001). On average, Pleuromamma spp. alone make up $15 \%$ of the total migrant biomass (Steinberg et al. 2000). Specific dry weight for E. messinensis was $0.38 \mathrm{mg}$ dry wt ind. ${ }^{-1}$. Mean values of $0.51 \mathrm{mg}$ dry wt ind. ${ }^{-1}$ for $P$. xiphias and $1.14 \mathrm{mg}$ dry wt ind. ${ }^{-1}$ for $T$. aequalis/E. brevis were determined previously (Steinberg et al. 2000). In general, total nocturnal zooplankton biomass at BATS is 1.5 to 2.5 times greater than during the day (Madin et al. 2001). Migrating biomass integrated over the upper $150 \mathrm{~m}$ (sum of all size ranges $>200 \mu \mathrm{m}$ ) ranges from 2 to $1299 \mathrm{mg}$ dry wt $\mathrm{m}^{-2}$ (mean $=231 \mathrm{mg}^{\mathrm{m} y \mathrm{wt} \mathrm{m}} \mathrm{m}^{-2}$ ) or 0.7 to $468 \mathrm{mg} \mathrm{C} \mathrm{m}^{-2}$ (mean $=$ $83 \mathrm{mg} \mathrm{C} \mathrm{m}^{-2}$ ) assuming organic $\mathrm{C}$ wt $=0.36 \times$ dry wt (Madin et al. 2001).

\section{Export flux}

To compare active POC/PON flux to passive POC/PON flux measured with sediment traps at $150 \mathrm{~m}$, we assumed that, on average, the migrants had to travel $75 \mathrm{~m}$ during their descent to penetrate the mixed layer. This distance corresponds to half of the deeper mixed layer depth at BATS, where mixing below $150 \mathrm{~m}$ only occurs during wintertime (Steinberg et al. 2000, 2001). This is likely a conservative estimate as the distance migrators travel might be considerably shorter than $75 \mathrm{~m}$ because the migrant community is found concentrated at the very base of the mixed layer above the subsurface chlorophyll maximum (Roman et al. 1993). Swimming speeds reported for the copepods Pleuromamma xiphias and Euchirella messinensis are 138 and $173 \mathrm{~m} \mathrm{~h}^{-1}$, respectively, and $191 \mathrm{~m} \mathrm{~h}^{-1}$ for the euphausiids (Wiebe et al. 1992), which is within the range reported for mixed migrant populations (72 to $216 \mathrm{~m} \mathrm{~h}^{-1}$; Heywood 1996). We calculated that the migrants require 24 to $33 \mathrm{~min}$ to descend $75 \mathrm{~m}$. Using this time span, and the measured GPT of Thysanopoda aequalis/Euphausia brevis, a mean of $18 \%$ (range $=0$ to $76 \%, \mathrm{n}=6$ ) of the initial gut content would remain in the guts of the euphausiids upon descent below the mixed layer. A higher fraction of the gut content would be transported below the mixed layer in both copepod
Table 4. Active POC and PON export flux due to migrator biomass at 150, 200 and $300 \mathrm{~m}$ at Bermuda Atlantic Time-series Study (BATS) site. Passive POC and PON flux: mean sediment trap flux at stated depths; active POC/PON flux: active POC and PON flux due to mean migrator biomass $\left(83 \mathrm{mg} \mathrm{C} \mathrm{m}^{-2}\right)$ at BATS; ranges are given in parentheses due to minimum $\left(0.7 \mathrm{mg} \mathrm{C} \mathrm{m}^{-2}\right)$ and maximum $\left(468 \mathrm{mg} \mathrm{C} \mathrm{m}^{-2}\right)$ migrator biomass at BATS; \%: migrant flux as a fraction of mean sediment trap flux at the corresponding depth. Note: C:N ratios of migrator fecal pellets were applied to active POC flux to obtain active PON flux (see 'Materials and methods')

\begin{tabular}{|lccc|}
\hline $\begin{array}{l}\text { Depth } \\
(\mathrm{m})\end{array}$ & $\begin{array}{c}\text { Passive POC } \\
\text { flux }\left(\mathrm{mg} \mathrm{C} \mathrm{m}^{-2}\right)\end{array}$ & $\begin{array}{c}\text { Active POC } \\
\text { flux }\left(\mathrm{mg} \mathrm{C} \mathrm{m}^{-2}\right)\end{array}$ & $\%$ \\
\hline 150 & 30 & $0.94(0.008-5.27)$ & $3(0.03-18)$ \\
200 & 22 & $0.80(0.007-4.52)$ & $4(0.03-21)$ \\
300 & 16 & $0.59(0.005-3.35)$ & $4(0.03-21)$ \\
& & & \\
Depth & Passive PON & Active PON & $\%$ \\
$(\mathrm{~m})$ & flux (mg N m$\left.{ }^{-2}\right)$ & flux (mg N m $\left.{ }^{-2}\right)$ & \\
\hline 150 & 5 & $0.18(0.002-1.02)$ & $4(0.04-20)$ \\
200 & 4 & $0.16(0.001-0.88)$ & $4(0.03-22)$ \\
300 & 3 & $0.12(0.001-0.65)$ & $4(0.03-22)$ \\
\hline
\end{tabular}

species, with a mean of $81 \%$ for $P$. xiphias (range $=67$ to $88 \%, \mathrm{n}=5$ ) and $76 \%$ for E. messinensis (range $=71$ to $83 \%, \mathrm{n}=5$ ). We also computed the amount of organic carbon remaining in migrators' guts at 200 and $300 \mathrm{~m}$ depth. GPT was corrected for the mean in situ temperature between 150 and $200 \mathrm{~m}\left(18.9^{\circ} \mathrm{C}\right)$ and between 200 and $300 \mathrm{~m}\left(18.4^{\circ} \mathrm{C}\right)$ using a $Q_{10}$ of 2.21 (Dam \& Peterson 1988). At $300 \mathrm{~m}$ depth, gut pigment remained in euphausiid guts in only 2 out of 6 experiments, amounting to an average of 7 and $27 \%$ of the initial gut pigment. All copepods in our experiments retained a substantial proportion of initial gut content upon their descent to $300 \mathrm{~m}$ with a mean of $57 \%$ (range $=32$ to $70 \%, \mathrm{n}=5$ ) and $51 \%$ (range $=7$ to $47 \%, \mathrm{n}=5$ ) for $P$. xiphias and E. messinensis, respectively.

Active POC flux at $150 \mathrm{~m}$ depth due to mean migrant biomass is equal to $3 \%$ of passive POC flux, with a range of 0.03 to $18 \%$ due to minimum and maximum migrant biomass (Table 4). Active PON flux at $150 \mathrm{~m}$ depth due to mean migrant biomass is equal to $4 \%$ of passive sediment trap PON flux, with a range of 0.04 to $20 \%$ due to minimum and maximum migrant biomass (Table 4).

\section{DISCUSSION}

\section{Gut passage times}

The GPT calculated from gut evacuation measurements depends upon the model (linear or exponential) 
Table 5. Summary of reported gut passage times (GPT) for zooplankton. Values are given as mean or range if available. In the majority of cited studies gut evacuation experiments were run for a certain time period to calculate GPT (range 30 to 420 min, $\mathrm{n}=23$; not including time span of incubation used by Pakhomov et al. (1997) for Euphausia superba of 12 to $24 \mathrm{~h}$ ); k: gut evacuation rate; Temp.: experimental temperature; GPT: gut passage time at incubation temperature; Corr. GPT: temperaturecorrected gut passage time for $20.5^{\circ} \mathrm{C}$ using a $Q_{10}=2.21$ (Dam \& Peterson 1988). When ranges of GPT are given, a mean was calculated from the minimum and maximum value. Note: differences in methodology such as corrections for different molecular weight of pigments, background fluorescence, or pigment destruction exist between the different studies

\begin{tabular}{|c|c|c|c|c|c|c|}
\hline & $\begin{array}{c}\mathrm{k} \\
\left(\min ^{-1}\right)\end{array}$ & $\begin{array}{l}\text { Temp. } \\
\left({ }^{\circ} \mathrm{C}\right)\end{array}$ & $\begin{array}{l}\text { GPT } \\
(\min )\end{array}$ & $\begin{array}{l}\text { Corr. GPT } \\
\text { (min) }\end{array}$ & Study area & Source \\
\hline \multicolumn{7}{|l|}{ Strong diel migrators } \\
\hline Metridia lucens & $0.014-0.024$ & $8.4-13.5$ & $42-71$ & 27 & Northeast Pacific & Batchelder (1986) \\
\hline Metridia lucens & $-^{\mathrm{a}}$ & $7.5-16$ & 300 & 152 & New York Bight & Smith \& Lane (1988) \\
\hline $\begin{array}{l}\text { Eucalanus elongatus and } \\
\text { Eucalanus enermis }\end{array}$ & $0.005-0.0054$ & $15-17$ & $185-200$ & 135 & North Pacific & Flint et al. (1991) \\
\hline $\begin{array}{l}\text { Metridia spp. and } \\
\text { Pleuromamma spp. }\end{array}$ & $0.0066-0.0098$ & $11.5-16$ & $102-150$ & 74 & Northeast Atlantic & Morales et al. (1993) \\
\hline Pleuromamma borealis & 0.011 & 13 & 91 & 50 & California Bight & Landry et al. (1994) \\
\hline Metridia gerlachei & 0.0081 & $0.5-1.5$ & 123 & 26 & Antarctic waters & Lopez \& Huntley (1995) \\
\hline $\begin{array}{l}\text { Metridia lucens and } \\
\text { Pleuromamma robusta }\end{array}$ & $0.0065-0.0090$ & 6.5 & $111-154$ & 44 & South Georgia & Atkinson et al. (1996) \\
\hline Euphausia superba & $0.0027-0.0045$ & 5 & $222-370$ & 87 & South Georgia & Atkinson \& Snyder (1997) \\
\hline Euphausia superba & $0.0022-0.0071$ & $-{ }^{\mathrm{b}}$ & $141-455$ & & South Georgia & Pakhomov et al. (1997) \\
\hline Mean & & & & 74 & & \\
\hline Pleuromamma xiphias & $0.0061-0.0128$ & 20 & $99-242$ & 191 & Sargasso Sea & This study \\
\hline Euchirella messinensis & $0.0082-0.0178$ & 21 & $88-153$ & 114 & Sargasso Sea & This study \\
\hline $\begin{array}{l}\text { Thysanopoda aequalis } \\
\text { and Euphausia brevis }\end{array}$ & $0.0130-0.0867$ & 20 & $15-99$ & 41 & Sargasso Sea & This study \\
\hline Mean & & & & 115 & & \\
\hline \multicolumn{7}{|l|}{ Seasonal/weak migrators } \\
\hline $\begin{array}{l}\text { Neocalanus plumchrus } \\
\text { and Neocalanus cristatus }\end{array}$ & $\begin{array}{c}0.0146-0.0388 \\
0.0183\end{array}$ & $\begin{array}{l}4-9.2 \\
8.5\end{array}$ & $\begin{array}{c}26-69 \\
55\end{array}$ & $\begin{array}{l}16 \\
21\end{array}$ & Bering Sea & Dagg \& Wyman (1983) \\
\hline Neocalanus plumchrus & 0.0093 & 8 & 108 & 40 & Subarctic Pacific & Dagg \& Walser (1987) \\
\hline Calanus finmarchicus & $-{ }^{\mathrm{a}}$ & $12-16$ & 30 & 18 & New York Bight & Smith \& Lane (1988) \\
\hline Calanus pacificus & 0.033 & $-^{\mathrm{b}}$ & 30 & & Dabob Bay & Dagg et al. (1989) \\
\hline Calanus finmarchicus & $0.0255-0.034$ & 10 & $29-39$ & 15 & Northeast Atlantic & Morales et al. (1991) \\
\hline Calanus pacificus & 0.027 & $13-15$ & 37 & 24 & North Pacific & Flint et al. (1991) \\
\hline Calanus pacificus & $0.039-0.109$ & $13-16$ & $9-26$ & 11 & California Bight & Landry et al. (1994) \\
\hline $\begin{array}{l}\text { Calanus simillimus and } \\
\text { Clausocalanus laticeps }\end{array}$ & $0.0095-0.027$ & 6.5 & $37-105$ & 23 & South Georgia & Atkinson et al. (1996) \\
\hline Calanus propinquus & $0.0033-0.0533$ & 4 & $19-303$ & 44 & Antarctic waters & Dubischar \& \\
\hline Calanoides acutus & $0.016-0.014$ & 4 & $63-72$ & 18 & & Bathmann (1997) \\
\hline Rhincalanus gigas & $0.0042-0.0158$ & 4 & $63-240$ & 33 & & \\
\hline Calanus propinquus & $0.011-0.0169$ & 2 & $59-90$ & 17 & Antarctic waters & Tirelli \& Mayzaud (1999) \\
\hline Calanoides acutus & $0.0138-0.0115$ & 2 & $73-87$ & 18 & & \\
\hline Rhincalanus gigas & 0.0114 & 2 & 88 & 20 & & \\
\hline Mean & & & & 23 & & \\
\hline \multicolumn{7}{|l|}{ Non-migrators } \\
\hline Eudiaptomus graciloides & $0.006-0.085$ & $4.5-19$ & $12-167$ & 45 & $\begin{array}{l}\text { North of } \\
\text { New Zealand }\end{array}$ & $\begin{array}{l}\text { Christoffersen \& } \\
\text { Jespersen (1986) }\end{array}$ \\
\hline Acartia tonsa & $0.039-0.048$ & 13.7 & $21-26$ & 13 & Laboratory culture & Kiorboe \& Tiselius (1987) \\
\hline Temora longicornis & $0.0065-0.044$ & $0-17$ & $23-154$ & 34 & Long Island Sound & Dam \& Peterson (1988) \\
\hline Calanus marshallae & $0.0387-0.0686$ & 10 & $15-26$ & 9 & Yaquina Bay & Ellis \& Small (1989) \\
\hline Calanus australis & 0.025 & 17 & 40 & 30 & North Pacific & Flint et al. (1991) \\
\hline $200-500 \mu \mathrm{m}$ size fraction ${ }^{\mathrm{c}}$ & $0.012-0.015$ & $10-14$ & $67-83$ & 38 & Northeast Atlantic & Morales et al. (1991) \\
\hline Acartia hudsonica & $0.0239-0.0518$ & $4-16$ & $16-42$ & 13 & Rhode Island & Wlodarczyk et al. (1992) \\
\hline Clausocalanus spp. & $0.039-0.088$ & $13-16$ & $13-26$ & 12 & California Bight & Landry et al. (1994) \\
\hline $\begin{array}{l}\text { Neocalanus tonsus and } \\
\text { Oithona spp. }\end{array}$ & $0.021-0.033$ & 6.5 & $30-48$ & 13 & South Georgia & Atkinson et al. (1996) \\
\hline Mean & & & & 23 & & \\
\hline
\end{tabular}


used to describe the decline in gut pigment concentrations over time, as well as the time span used for regression analysis. In this study, replication of experiments for copepods and euphausiids allowed us to select the appropriate model and time span by statistical comparison. Our results support apparent agreement in the literature that gut evacuation processes are best described by an exponential model over the first phase of the gut evacuation curve (see cited studies in Table 5).

Our results also support previous work that GPT of migrating zooplankton are longer than those of their surface-living counterparts (Smith \& Lane 1988, Morales et al. 1993, Atkinson et al. 1996, Morales 1999). GPT for the common migrators at BATS examined in this paper ranged from 41 to $191 \mathrm{~min}$, which is within the range reported for other migrant zooplankton (27 to $152 \mathrm{~min}$ ) but exceeds values measured for non-migrants (range $=9$ to $38 \mathrm{~min}$ ) by a factor of about 6 (Table 5).

Higher GPT in vertically migrating zooplankton may be an evolutionary consequence of predator avoidance, one of the major stimuli for vertical migration. Atkinson et al. (1996) found a 5-fold range in weightspecific GPT for 9 different copepod species/stages within a single community. Variations in GPT were correlated with the extent of daily migratory behavior with the longest GPT measured for strong migrants. Atkinson et al. (1996) suggest that for some epipelagic copepods, which exhibit nocturnal feeding (Christoffersen \& Jespersen 1986, Wlodarczyk et al. 1992), a short GPT could ensure copepod guts to be empty after sunrise, making copepods less visible to predators. The idea that nocturnal feeding by non-migrant copepods is a possible strategy for reducing mortality from visual predation is further argued by Tsuda et al. (1998). Their experiments show that during daylight the risk of being eaten for copepods Acartia and Pseudocalanus is significantly higher when their guts are full. On the contrary, copepods that migrate to low light levels could afford to spend a longer time processing their food, resulting in a higher assimilation efficiency (Atkinson et al. 1996). In some deep-sea copepods, morphological adaptations like elongated mid-guts (Nishida et al. 1991) might also lead to longer GPTs and higher assimilation efficiencies.

It has been suggested that amongst vertical migrators, only the larger zooplankton and fish have a GPT long enough to actively transport particulate organic matter to greater depths (Angel 1985, Longhurst \& Harrison 1988). Ellis (1991) found an inverse relationship between copepod body length and gut evacuation rates (i.e. larger copepods had longer GPTs) and was able to explain a significant part of the variance in gut evacuation rates among copepod species from the
North Pacific Ocean by their differences in body size. We found no significant correlation between animal size and GPT for the migrant species examined in our study. However, the euphausiids are more than twice the size of the copepods used in our study and exhibited the shortest GPT (mean of $41 \mathrm{~min}$ ). Angel (1989) found a similarly short GPT of 30 min for the adult euphausiid Meganyctiphanes norvegica. The fact that differences in GPT are not merely a reflection of body size has previously been reported. Analyzing their own results and a wide range of literature data (after correction for different experimental temperature), Morales et al. (1990) noted no correlation between gut evacuation rate and copepod size. Landry et al. (1994) also reported no apparent effect of size on GPT for Calanus pacificus.

GPT may also depend upon temperature (Dam \& Peterson 1988), food concentration and quality (Dagg \& Walser 1987, Dagg et al. 1997, Irigoien 1998), food preferences (Batchelder 1986), and feeding strategy and developmental stage (Atkinson et al. 1996, Morales 1999). Thus, considerable intraspecific variability in GPT can be found depending on geographical region, as reported for the migrating copepod Metridia lucens (range $=27$ to $152 \mathrm{~min}$; Batchelder 1986, Smith \& Lane 1988, Atkinson et al. 1996; Table 5). We cannot explain the lack of correlation between temperature and GPT in our experiments other than the range in experimental temperature was small compared to the wide range zooplankton experience during daily migrations. Changes in 1 or more of the determining parameters may effect GPT in different species or groups to various degrees, making interspecies comparison difficult. Moreover, few analyses of GPT of strong migrants exist for comparison. In our study, GPT varies significantly (4.5-fold) between different migrating species within a single community. As these migrants experience more or less the same physical and biological environment, other factors such as diet preferences may play an important role in determining GPT.

\section{Diet preferences}

Most zooplankton are able to feed opportunistically by grazing on phytoplankton or microzooplankton, preying on each other, feeding on detritus, or reingesting fecal pellets, i.e. coprophagy (e.g. Paffenhoefer \& Knowles 1979, Lampitt et al. 1993, Steinberg 1995). Many migrants are able to switch diet depending on the availability of food to meet metabolic requirements (Kleppel et al. 1988, Lampitt et al. 1993). Arashkevich (1969) found that for copepods mixed feeding generally becomes increasingly important 
with depth. Thus, to avoid underestimation of POC flux by only considering plant material ingested, we compared plant ingestion rates (measured by the gut fluorescence method) with total ingestion rates (derived from $\mathrm{CHN}$ analysis of fecal pellets).

The amount of carbon derived from autotrophic prey was low for all species, with 71 to $85 \%$ of the migrant diets composed of non-plant material (Table 3). Gut content analyses of these migrating species confirmed that they feed on a variety of food sources other than phytoplankton (Schnetzer \& Steinberg 2002). Generally these results are also consistent with previous studies on feeding preferences of these taxa. Bennet \& Hopkins (1989) examined gut contents of 4 different species of the genus Pleuromamma from the Eastern Gulf of Mexico, including P. xiphias, and found that the copepods utilized a wide variety of food sources (plants, other animals and detrital material). Arashkevich (1969) studied feeding appendages of copepods and described copepod families Metridiidae and Aetideidae as mixed feeders. Members of the genus Euchirella, including E. messinensis, show special morphological adaptations related to raptorial feeding (Von Vaupel Klein \& Koomen 1994). Euphausiid feeding behavior is strongly influenced by the quantity and quality of food available (Gibbons et al. 1999). Some euphausiid species may obtain nearly half of the carbon ingested by preying on copepods even at high ambient phytoplankton concentrations (Stuart \& Pillar 1990).

Feeding preferences of migrants can have a significant effect on the quality of feces released at depth and thus its nutritive value for the mesopelagic biota. Freshly released fecal pellets could be a valuable food source in contrast to passively sinking pellets, which are decomposed while sinking through the water column at rates of $\sim 50$ to $100 \mathrm{~m} \mathrm{~d}^{-1}$ (Honjo \& Roman 1978, Paffenhoefer \& Knowles 1979) or while retained in surface waters (Alldredge et al. 1987). Experiments with freshly collected fecal pellets indicate microbial activity is intense in the first $2 \mathrm{~d}$, and thereafter most activity has terminated (e.g. Pomeroy et al. 1984), suggesting much of the labile material on pellets is consumed rapidly. Most DOC leaches from copepod fecal pellets within the first $48 \mathrm{~h}$ (Urban-Rich 1999); thus, the majority of DOC from fecal pellets will be leached as the pellet is settling through the upper $150 \mathrm{~m}$. This DOC would be available for the mesopelagic microbial community when migrators release fresh fecal pellets at depth. The C:N ratios of fecal pellets freshly produced by migrants in this study ranged from 5.7 to 6.3 , and are within the lower range of ratios reported for copepods (Morales 1987), indicating that they could be a nutritious food source.

Comparing the amount of plant carbon ingested (gut fluorescence technique) with the total carbon ingestion
(CHN analysis) allows the assessment of autotrophic versus heterotrophic diet. This comparison, however, depends on the following assumptions: First, we did not measure pigment destruction directly in our experiments and corrected for possible chl a loss using a literature value of $33 \%$. Second, we used a C:chl a ratio of 50 to convert chl a into organic carbon. Our correction for pigment destruction is based on literature surveys conducted by Dam \& Peterson (1988) and Ellis (1991) (summarized in their Table I and Table II.2, respectively) that show that $33 \%$ is near the pigment destruction values reported in the majority of studies using the gut fluorescence method. A comparison of plant ingestion rates in zooplankton examined in this study with those previously reported for migrators suggests that applying this literature value to our data is reasonable. Plant ingestion rates ranged from 0.02 to $0.15 \mathrm{ng}$ chl a ( $\mu$ g body $\mathrm{C})^{-1} \mathrm{~h}^{-1}$ ( 6 to $20 \mathrm{ng}$ chl a equiv. ind..$^{-1} \mathrm{~h}^{-1}$ ) and correspond to those reported by Roman et al. (1993) for mesozooplankton $(>200 \mu \mathrm{m})$ in the upper $160 \mathrm{~m}$ at BATS (0.01 and $0.12 \mathrm{ng}$ chl $a$ [ $\mu \mathrm{g}$ body C] ${ }^{-1} \mathrm{~h}^{-1}$ for August and March/April, respectively). Plant ingestion rates in our study are slightly higher but also comparable to other previously published ingestion rates for migrators Metridia pacifica ( 0.2 to $5.5 \mathrm{ng}$ chl a equiv. ind. ${ }^{-1} \mathrm{~h}^{-1}$, Batchelder 1986), Pleuromamma and Metridia spp. (1.9 to $5.6 \mathrm{ng}$ chl a equiv. ind. ${ }^{-1} \mathrm{~h}^{-1}$, Morales et al. 1993) and Metridia gerlachi (1.9 to $4.9 \mathrm{ng}$ chl a equiv. ind.$^{-1} \mathrm{~h}^{-1}$, Lopez \& Huntley 1995). Goericke \& Welschmeyer (1998) documented that C:chl a ratios in the Sargasso Sea range from about 160 at the surface to 33 at the $1.6 \%$ light level. Since migrant zooplankton reside at the base of the mixed layer near the chlorophyll maximum (Roman et al. 1993), we assumed a C:chl a ratio of 50, which is equal or close to values applied in several other studies (e.g. Dagg \& Grill 1980, Dagg \& Wyman 1983, Wlodarczyk et al. 1992, Landry et al. 1994). Applying a higher C:chl a ratio or higher values for pigment destruction to our data results in an increase in ingestion rates based on gut pigment data by $\sim 3$-fold. This would consequently alter the proportion of autotrophic versus heterotrophic prey in migrator diet and only $\sim 10$ to $55 \%$ of the ingested carbon would derive from carnivory/detritivory, which is low compared to previous studies (Small \& Ellis 1992, Atkinson et al. 1996). However, an increase of ingestion rates by 3 -fold would not affect our GPT estimates or active flux calculations.

\section{Active POC/PON flux}

Upon leaving a mixed layer of $150 \mathrm{~m}$, a significant portion of initial gut pigment (18 to $81 \%$ ) remained in the guts of the common migrators examined in this 
study. Similarly, Atkinson et al. (1996) determined that 61 and $77 \%$ of the initial gut pigment remained in the guts of Metridia lucens and Pleuromamma robusta, respectively, after a $1 \mathrm{~h}$ descent below the thermocline (>100 m) in South Georgia (Antarctica). Dagg et al. (1989) determined that Calanus pacificus retains 10\% and $M$. lucens $8 \%$ of surface ingested pigment upon reaching the deep layer $(>75 \mathrm{~m}$ ) in Dabob Bay (Washington) by measuring gut fluorescence of migrators collected at different depths. Although to a lesser degree in the latter study, the retention of material in the guts of migrating zooplankton suggests that fecal pellet production by migrators at depth could significantly contribute to carbon and nitrogen export from the euphotic zone.

Diel vertically migrating zooplankton contribute to carbon and nitrogen export by respiring, excreting and defecating surface-ingested material below the mixed layer, and by mortality at depth (Longhurst et al. 1990, Dam et al. 1995, Atkinson et al. 1996, Le Borgne \& Rodier 1997, Zhang \& Dam 1997, Morales 1999, Steinberg et al. 2000). Our study shows that active POC flux due to defecation below $150 \mathrm{~m}$ depth is, on average, $3 \%$ of total organic $\mathrm{C}$ flux and reaches a maximum of $18 \%$ of the POC flux measured by sediment traps at BATS (Table 4). While potentially significant during periods of high migrating biomass, active flux of POC by migrators is lower compared to other active fluxes measured at BATS. Active flux via respiration and excretion contributes significantly to export flux at BATS, with estimates of inorganic carbon flux ranging from 18 to $70 \%$ of sediment trap flux (Dam et al. 1995). In a subsequent study at BATS, Steinberg et al. (2000) found DIC and DOC flux combined equal to a mean of $8 \%$ and a maximum of $39 \%$ of mean sediment trap flux at $150 \mathrm{~m}$. (Discrepancies in estimates are largely due to a higher migrating biomass reported by Dam et al. 1995.)

It should be noted that incubating migrators in $0.2 \mu \mathrm{m}$ filtered seawater to measure GPT might be a source of error in determining active export, if zooplankton continuously feed during their downward migration, as food passes through the gut more slowly as the food level in the gut decreases (Irigoien 1998). However, studies comparing gut evacuation rates of feeding versus non-feeding copepods show little difference over the initial period of incubation (Christofferson \& Jespersen 1986, Ellis \& Small 1989). If zooplankton do continuously feed during their downward migration, we will have underestimated export flux, since animal guts would be refilled just before leaving the upper mixed layer.

While migrants actively transport surface-ingested POC/PON to depth in their guts, they also contribute to passive flux, due to the production of sinking fecal pellets released during the night spent in surface waters.
For example, with a gut passage time of $3 \mathrm{~h}$, nocturnal fecal pellet production of Pleuromamma xiphias theoretically derives from 4 gut loads per individual (assuming a feeding period of $12 \mathrm{~h}$ ). Thysanopoda aequalis/Euphausia brevis with a GPT of $0.7 \mathrm{~h}$ would release fecal pellets derived from 17 gut loads per night. Considerably less fecal carbon is released at depth by the migrators; they start their descent with a maximum of 1 full gut load and only a portion of that remains in guts for defecation at depth. We calculated the mean amount of POC defecated by the 4 species of migrators during their surface residence time (12 h) and extrapolated to total migrant biomass, which resulted in a mean passive POC flux of $9 \mathrm{mg} \mathrm{C} \mathrm{m}^{-2} \mathrm{~d}^{-1}$, exceeding active POC flux $\sim 10$-fold (Table 4).

To the best of our knowledge, only 3 other studies have calculated active export of particulate organic matter by strong vertical migrators. Morales (1999) estimated an active POC flux of 0.9 to $21 \mathrm{mg} \mathrm{C} \mathrm{m}^{-2} \mathrm{~d}^{-1}$ in the North Atlantic, which generally exceeds that at BATS $\left(0.01\right.$ to $5.4 \mathrm{mg} \mathrm{C} \mathrm{m}^{-2} \mathrm{~d}^{-1}$ at $150 \mathrm{~m}$ depth, Table 4). Normalized for the difference in migrant biomass ( $400 \mathrm{mg} \mathrm{C} \mathrm{m}^{-2}$ in the North Atlantic [Morales 1999] compared to $\sim 83 \mathrm{mg} \mathrm{C} \mathrm{m}^{-2}$ in the Sargasso Sea; Table 4), active POC flux at BATS would amount to $\sim 0.1$ to $25 \mathrm{mg} \mathrm{C} \mathrm{m}^{-2} \mathrm{~d}^{-1}$, comparable to the North Atlantic site. Morales (1999) based her calculations on daily consumption rates (12 h) of Metridia spp. and Pleuromamma spp., assuming that fecal carbon corresponds to $30 \%$ of total organic carbon consumed. As in our study, these rates were then applied to the total migrant biomass. However, differences in the calculation of flux rates in both studies are evident. First, Morales (1999) based calculations of active POC flux on defecation rates derived from daily $(12 \mathrm{~h})$ consumption rates. This method does not distinguish between fecal pellets produced in the surface waters during nocturnal feeding which passively sink out, and material transported below the mixed layer in migrators' guts. Thus, this approach results in an overestimation of active POC flux. On the other hand, active POC flux in Morales (1999) was based on plant pigment ingestion rates only. This approach most likely underestimates active export flux since a significant proportion of the diet can be nonautotrophic, as suggested in the present study. Overall, active POC flux in the North Atlantic and the Sargasso Sea are highly comparable when the disparity between migrating biomass in the 2 environments is considered. Active POC flux in the North Atlantic corresponds to approximately 0.3 to $6.7 \%$ of passive POC flux (calculated from Table IV in Morales 1999), similar to our study (mean of $3 \%$ of passive POC flux, Table 4 ).

In an earlier study in the Northeast Atlantic, active POC flux due to a migrating population of the amphipod Themisto compressa was estimated at $2 \%$ of sedi- 
ment trap flux at $100 \mathrm{~m}$ depth (Lampitt et al. 1993). As in our study, results from fecal pellet production experiments and data on migration patterns of the amphipod were used to calculate the amount of carbon defecated once migrators descended below $100 \mathrm{~m}$. When Lampitt et al. (1993) extrapolated their results to the total migrant community, they found that active POC flux corresponded to $5 \%$ of passive POC flux, a value comparable to our results (Table 4).

In another study, Atkinson et al. (1996) calculated an active POC flux of $0.4 \mathrm{mgC} \mathrm{m}^{-2} \mathrm{~d}^{-1}$ due solely to migrating copepods Pleuromamma robusta and $\mathrm{Me}$ tridia lucens at the Polar Frontal Zone north of South Georgia (Antarctica). Lacking data on total migrant zooplankton biomass for the South Georgia location and as Atkinson et al. (1996) only account for plant carbon transported, we compare the amount of plant carbon, actively transported by the individual copepods in theirs and our study. Mean values for gut content and GPT for P. robusta and M. lucens were taken from Figs. 4 \& 6 in Atkinson et al. (1996), and mean GPTs were corrected for the temperature difference between the Polar Front waters $\left(6.5^{\circ} \mathrm{C}\right)$ and the Sargasso Sea $\left(20.5^{\circ} \mathrm{C}\right)$ using a $Q_{10}$ of 2.21 (Dam \& Peterson 1988). If we assume that copepods at the Polar Front travel the same distance and with the same speed as the copepods in our study, active POC flux due to $P$. robusta and $M$. lucens would amount to 5.47 and $0.19 \mu \mathrm{g}$ plant $\mathrm{C}(\mathrm{mg} \text { body } \mathrm{C})^{-1}$. These flux rates are highly comparable to those of Pleuromamma xiphias and Euchirella messinensis with 4.27 and $2.82 \mu \mathrm{g}$ plant $\mathrm{C}(\mathrm{mg} \text { body } \mathrm{C})^{-1}$ at BATS.

Active export depends on both total migrant biomass and the composition of the migrant community. Although our calculations are based on GPT measured for migrants belonging to the larger size classes ( $>2 \mathrm{~mm}$ ), we suggest that they are likely representative of much of the migrant community, as zooplankton $>2 \mathrm{~mm}$ comprise $56 \%$ of the total migrant community at BATS (Madin et al. 2001). If larger zooplankton do have longer GPTs, we would have overestimated total active POC/PON flux by extrapolating GPT for the larger size classes to the total migrant community at BATS. Thus, our method does not correct for the higher mass-specific metabolic rates of smaller zooplankton (Al-Mutairi \& Landry 2001). We did not find any significant relationship between size and GPT for migrating zooplankton in our study, and except for Ellis (1991), no other study supports such a relationship. As there are insufficient data available, effects of migrator size on GPT must be further investigated.

In conclusion, active POC/PON flux at BATS is on average low; however, during periods of high migrant biomass it can contribute significantly to overall carbon and nitrogen export and should be considered in export budgets. In addition, due to its potentially high nutritive quality, actively exported particulate organic material may prove to be a valuable food source for the mesopelagic biota.

Acknowledgements. Special thanks to the captain, crew and marine technicians of the RV 'Weatherbird II' for help with sample collection. Technical assistance given by Bermuda Atlantic Time-series Study (BATS) technicians is greatly appreciated. We thank G. J. Herndl and 4 anonymous reviewers for helpful suggestions and comments on the manuscript. This work was supported by scholarships from the Munson Foundation, the Roger Thayer Stone Fellowship, the International Relations Office (University of Vienna), grants from the State of Upper Austria (Sonderfoerderung des Landes Oberoesterreich), and partly by NSF grant OCE-9801950 (BATS). We are also grateful to Larry Madin for making available the BATS zooplankton time-series data (NSF OCE9202336).This paper is BBSR contribution number 1610 and US JGOFS contribution number 698. The work is partial fulfillment of the requirements towards a $\mathrm{PhD}$ degree at the University of Vienna by A.S.

\section{LITERATURE CITED}

Alldredge AL, Gotschalk CC, MacIntyre S (1987) Evidence of sustained residence of macrocrustacean fecal pellets in surface waters off Southern California. Deep-Sea Res 34: 1641-1652

Al-Mutairi H, Landry MR (2001) Active export of carbon and nitrogen at Station ALOHA by diel migrant zooplankton. Deep-Sea Res II 48:2083-2103

Angel MV (1985) Vertical migrations in the oceanic realm: possible causes and probable effects. In: Rankin MA, Checkley D, Cullen J, Kitting C, Thomas P (eds) Migration: mechanism and adaptive significance. Contrib Mar Sci 68:45-70

Angel MV (1989) Does mesopelagic biology affect the vertical flux? In: Berger WH, Smetacek VS, Wefer G (eds) Productivity of the ocean: present and past. Dahlem Conference, John Wiley \& Sons, New York, p 155-173

Arashkevich YG (1969) The food and feeding of copepods in the Northwestern Pacific. Oceanology 9:695-709

Atkinson A, Snyder R (1997) Krill-copepod interactions at South Georgia, Antarctica, I. Omnivory by Euphausia superba. Mar Ecol Prog Ser 160:63-76

Atkinson A, Ward P, Murphy EJ (1996) Diel periodicity of Subantarctic copepods: relationships between vertical migration, gut fullness and gut evacuation rate. J Plankton Res 18:1387-1405

Batchelder HP (1986) Phytoplankton balance in the oceanic subarctic Pacific: grazing impact of Metridia pacifica. Mar Ecol Prog Ser 34:213-225

Bennett JL, Hopkins TL (1989) Aspects of the ecology of the calanoid copepod genus Pleuromamma in the eastern Gulf of Mexico. Contrib Mar Sci 31:119-136

Bochdansky AB, Deibel D (2001) Consequences of model specification for the determination of gut evacuation rates: redefining the linear model. Can J Fish Aquat Sci 58: 1032-1042

Christoffersen K, Jespersen A (1986) Gut evacuation rates and ingestion rates of Eudiaptomus graciloides measured by means of the gut fluorescence method. J Plankton Res 8:973-983 
Conover RJ (1978) Transformation of organic matter. In: Kinne O (ed) Marine ecology, Vol 4, Dynamics. John Wiley \& Sons, Chichester, p 221-456

Conover RJ, Durvasula R, Roy S, Wang R (1986) Probable loss of chlorophyll-derived pigments during passage through the gut of zooplankton, and some of the consequences. Limnol Oceanogr 31:878-887

Dagg MJ, Grill DW (1980) Natural feeding of Centropages typicus females in the New York Bight. Limnol Oceanogr 25:597-609

Dagg MJ, Walser WE Jr (1987) Ingestion, gut passage, and egestion by the copepod Neocalanus plumchrus in the laboratory and in the subarctic Pacific Ocean. Limnol Oceanogr 32:178-188

Dagg MJ, Wyman KD (1983) Natural ingestion rates of the copepods Neocalanus plumchrus and N. cristatus calculated from gut contents. Mar Ecol Prog Ser 13:37-46

Dagg MJ, Frost BW, Walser WE Jr (1989) Copepod diel migration, feeding, and the vertical flux of phaeopigments. Limnol Oceanogr 34:1062-1071

Dagg MJ, Frost BW, Newton JA (1997) Vertical migration and feeding behavior of Calanus pacificus females during a phytoplankton bloom in Dabob Bay, US. Limnol Oceanogr 42:974-980

Dam HG, Peterson WT (1988) The effect of temperature on the gut clearance rate constant of planktonic copepods. J Exp Mar Biol Ecol 123:1-14

Dam HG, Roman MR, Youngbluth MJ (1995) Downward export of respiratory carbon and dissolved inorganic nitrogen by diel-migrant mesozooplankton at the JGOFS Bermuda time-series station. Deep-Sea Res I 42: 1187-1197

Dubischar CD, Bathmann UV (1997) Grazing impact of copepods and salps on phytoplankton in the Atlantic sector of the Southern Ocean. Deep-Sea Res II 44:415-433

Ellis SG (1991) Seasonal dynamics and allometric considerations of feeding and food processing for macrozooplankton in the Northeast Pacific Ocean. PhD thesis, Oregon State University, Corvallis

Ellis SG, Small LF (1989) Comparison of gut evacuation rates of feeding and non-feeding Calanus marshallae. Mar Biol 103:175-181

Flint MV, Drits AV, Pasternak AF (1991) Characteristic features of body composition and metabolism in some interzonal copepods. Mar Biol 111:199-205

Fowler SW, Knauer GA (1986) Role of large particles in the transport of elements and organic compounds through the oceanic water column. Prog Oceanogr 16:147-194

Gibbons MJ, Spiridonov VA, Tarling GA (1999) Euphausiaceae. In: Boltovsky D (ed) South Atlantic zooplankton, Vol I. Backhuys Publishers, Leiden, p 1241-1279

Goericke R, Welschmeyer NA (1998) Response of Sargasso Sea phytoplankton biomass, growth rates and primary production to seasonally varying physical forcing. J Plankton Res 20:2233-2249

Hays GC, Harris RP, Head RN (1997) The vertical nitrogen flux caused by zooplankton diel vertical migration. Mar Ecol Prog Ser 160:57-62

Heywood KJ (1996) Diel vertical migration of zooplankton in the Northeast Atlantic. J Plankton Res 18:163-184

Honjo S, Roman MR (1978) Marine copepod fecal pellets: production, preservation and sedimentation. J Mar Res 36: $45-56$

Irigoien X (1998) Gut clearance rate constant, temperature and initial gut contents: a review. J Plankton Res 20: 997-1003

Kiørboe T, Tiselius PT (1987) Gut clearance and pigment destruction in a herbivorous copepod, Acartia tonsa, and the determination of in situ grazing rates. J Plankton Res 9:525-534

Kleppel GS, Frazel D, Pieper RE, Holliday DV (1988) Natural diets of zooplankton off southern California. Mar Ecol Prog Ser 49:231-241

Lampitt RS, Wishner KF, Turley CM, Angel MV (1993) Marine snow studies in the Northeast Atlantic Ocean: distribution, composition and role as a food source for migrating plankton. Mar Biol 116:689-702

Landry MR, Lorenzen CJ, Peterson WK (1994) Mesozooplankton grazing in the Southern California Bight. II. Grazing impact and particulate flux. Mar Ecol Prog Ser 115:73-85

Le Borgne R, Rodier M (1997) Net zooplankton and the biological pump: a comparison between the oligotrophic and mesotrophic equatorial Pacific. Deep-Sea Res II 44: 2003-2023

Longhurst AR, Harrison WG (1988) Vertical nitrogen flux from the oceanic photic zone by diel migrant zooplankton and nekton. Deep-Sea Res 35:881-889

Longhurst AR, Harrison WG (1989) The biological pump: profiles of plankton production and consumption in the upper ocean. Prog Oceanogr 22:47-123

Longhurst AR, Bedo AW, Harrison WG, Head EJH, Sameoto DD (1990) Vertical flux of respiratory carbon by oceanic diel migrant biota. Deep-Sea Res 37:685-694

Lopez MDG, Huntley ME (1995) Feeding and diel vertical migration cycles of Metridia gerlachei (Giesbrecht) in coastal waters of the Antarctic Peninsula. Polar Biol 15: $21-30$

Mackas D, Bohrer R (1976) Fluorescence analysis of zooplankton gut contents and an investigation of diel feeding patterns. J Exp Mar Biol Ecol 25:77-85

Madin LP, Horgan EF, Steinberg DK (2001) Zooplankton at the Bermuda Atlantic Time-series Study (BATS) Station: diel, seasonal and interannual variation in biomass, 1994-1998. Deep-Sea Res II 48:2063-2082

Michaels AF, Silver MW (1988) Primary production, sinking fluxes and the microbial food web. Deep-Sea Res 35: 473-490

Morales CE (1987) Carbon and nitrogen content of copepod faecal pellets: effect of food concentration and feeding behavior. Mar Ecol Prog Ser 36:107-114

Morales CE (1999) Carbon and nitrogen fluxes in the oceans: the contribution by zooplankton migrants to active transport in the North Atlantic during the Joint Global Ocean Flux Study. J Plankton Res 21:1799-1808

Morales CE, Bautista B, Harris RP (1990) Estimates of ingestion in copepod assemblages: gut fluorescence in relation to body size. In: Barnes M, Gibson RN (eds) Trophic relationships in the marine environment. Proc 24th Eur Mar Biol Symp. Aberdeen University Press, Scotland, p 565-577

Morales CE, Bedo A, Harris RP, Tranter PRG (1991) Grazing of copepod assemblages in the north-east Atlantic: the importance of the small size fraction. J Plankton Res 13: $455-472$

Morales CE, Harris RP, Head RN, Tranter PRG (1993) Copepod grazing in the oceanic northeast Atlantic during a 6 week drifting station: the contribution of size classes and vertical migrants. J Plankton Res 15:185-211

Nishida S, Oh BC, Nemoto T (1991) Midgut structure and food habits of the mesopelagic copepods Lophothrix frontalis and Scottocalanus securifrons. Proceedings of the 4th International Conference on Copepoda. Bull Plankton Soc Jpn (Spec Vol):527-534 
Paffenhoefer GA, Knowles SC (1979) Ecological implications of fecal pellet size, production and consumption by copepods. J Mar Res 37:35-49

Pakhomov EA, Perissinotto R, Froneman PW, Miller DGM (1997) Energetics and feeding dynamics of Euphausia superba in the South Georgia region during the summer of 1994. J Plankton Res 19:399-423

Parsons TR, Maita Y, Lalli CM (1984) A manual of chemical and biological methods for seawater analysis. Pergamon Press, Oxford

Pasternak AF (1994) Gut fluorescence in herbivorous copepods: an attempt to justify the method. Hydrobiologia 292/293:241-248

Perissinotto R, Pakhomov EA (1996) Gut evacuation rates and pigment destruction in the Antarctic krill Euphausia superba. Mar Biol 125:47-54

Pomeroy LR, Hanson RB, McGillivary PA, Sherr BF, Kirchman D, Deibel D (1984) Microbiology and chemistry of fecal products of pelagic tunicates: rates and fates. Bull Mar Sci 35:426-439

Roman MR, Dam HG, Gauzens AL, Napp JM (1993) Zooplankton biomass and grazing at the JGOFS Sargasso Sea time series station. Deep-Sea Res I 40:883-901

SAS (1985) SAS user's guide statistics. SAS Inst, Cary, NC

Schnetzer A, Steinberg DK (2002) Natural diets of vertically migrating zooplankton in the Sargasso Sea. Mar Biol (in press)

Small LF, Ellis SG (1992) Fecal carbon production by zooplankton in Santa Monica Basin: the effects of body size and carnivorous feeding. Prog Oceanogr 30:197-222

Smith SL, Lane PVZ (1988) Grazing of the spring diatom bloom in the New York Bight by the calanoid copepods Calanus finmarchus, Metridia lucens and Centropages typicus. Cont Shelf Res 8:485-509

Steinberg DK (1995) Diet of copepods (Scopalatum vorax) associated with mesopelagic detritus (giant larvacean houses) in Monterey Bay, California. Mar Biol 122: 571-584

Steinberg DK, Carlson CA, Bates NR, Goldwaith SA, Madin LP, Michaels AF (2000) Zooplankton vertical migration and

Editorial responsibility: Otto Kinne (Editor),

Oldendorf/Luhe, Germany the active transport of dissolved organic and inorganic carbon in the Sargasso Sea. Deep-Sea Res I 47:137-158

Steinberg DK, Carlson CA, Bates NR, Johnson RJ, Michaels AF, Knap AH (2001) Overview of the US JGOFS Bermuda Atlantic Time-series Study (BATS): a decade-scale look at ocean biology and biogeochemistry. Deep-Sea Res II 48: 1405-1447

Stuart V, Pillar SC (1990) Diel grazing patterns of all ontogenetic stages of Euphausia lucens and in situ predation rates of copepods in the Southern Benguela upwelling region. Mar Ecol Prog Ser 64:227-241

Takatsuji H, Hamasaki K, Toda T, Taguchi S (1997) Improved technique for the gut fluorescence method in a feeding study of small zooplankton. J Plankton Res 19:159-165

Tirelli V, Mayzaud P (1999) Gut evacuation rates of Antarctic copepods during austral spring. Polar Biol 22:197-200

Tsuda A, Saito H, Hirose T (1998) Effect of gut content on the vulnerability of copepods to visual predation. Limnol Oceanogr 43:1944-1947

Urban-Rich J (1999) Release of dissolved organic carbon from copepod fecal pellets in the Greenland Sea. J Exp Mar Biol Ecol 232:107-124

Von Vaupel Klein JC, Koomen P (1994) The possible origin of mucus jets used for immobilizing prey in species of Euchirella (Copepoda, Calanoida, Aetideidae). I. Theoretical considerations in relation to swimming and feeding behaviour. Crustaceana 66:184-204

Wiebe PH, Copley NJ, Boyd SH (1992) Coarse-scale horizontal patchiness and vertical migration of zooplankton in Gulf Stream warm-core ring 82-H. Deep-Sea Res (Suppl 1) 39:S247-S278

Wlodarczyk E, Durbin AG, Durbin EG (1992) Effect of temperature on lower feeding thresholds, gut evacuation rate, and diel feeding behavior in the copepod Acartia hudsonica. Mar Ecol Prog Ser 85:93-106

Zar JH (1984) Biostatistical analysis. Prentice-Hall, Englewood Cliffs, NJ

Zhang X, Dam HG (1997) Downward export of carbon by diel migrant mesozooplankton in the central equatorial Pacific. Deep-Sea Res II 44:2191-2202

Submitted: November 15, 2000; Accepted: November 15, 2001 Proofs received from author(s): April 30, 2002 